\title{
COVID-19 Readiness and Career Aspirations of South Indian Medical Students: A Cross-Sectional Survey Study
}

\author{
Manu Pradeep (1D \\ Sandeep Surendran $\mathbb{D}^{2}$ \\ Bhadra Rema (D) $^{3}$ \\ Niharika Binesh (D) $^{3}$ \\ Prakruthi P Reji $\mathbb{1 D}^{3}$ \\ 'Department of Pharmacology, Amrita \\ Institute of Medical Sciences, Amrita \\ Vishwa Vidyapeetham, Kochi, Kerala, \\ India; ${ }^{2}$ Department of Rheumatology, \\ Amrita Institute of Medical Sciences, \\ Amrita Vishwa Vidyapeetham, Kochi, \\ Kerala, India; ${ }^{3}$ Amrita School of Medicine, \\ Amrita Institute of Medical Sciences, \\ Amrita Vishwa Vidyapeetham, Kochi, \\ Kerala, India
}

Purpose: The second wave of COVID-19 devastated the medical sector on India and the government has implored medical students to aid the frontline workforce. This study aims to assess the knowledge, attitude and practice (KAP) of South Indian Medical students regarding the COVID-19 pandemic and their career aspirations.

Patients and Methods: This is an online questionnaire based, cross-sectional study featuring a pre-validated questionnaire with a KAP section and a career aspiration survey section, which was distributed to South Indian medical schools between November and December 2020. Three hundred and four responses were included for analysis.

Results: Good knowledge levels were seen in $65.5 \%$ of participants, $51 \%$ had good attitude scores and $80.6 \%$ had good practice scores. The mean KAP score was $14.81 \pm 1.77 .1 .3 \%$ of the respondents had low level KAP scores, 57.2\% had moderate level KAP scores and $41.4 \%$ of them had good level KAP scores. Majority aspired to continue post graduate medical training in Clinical medicine in India $(\mathrm{n}=116,38.2 \%)$, followed by Clinical Medicine outside India ( $=80,26.3 \%)$. Students who chose "Research Work" (average rank [AR] = 192.70), "Clinical Medicine outside India" ( $A R=173.64)$ "Undecided" ( $A R=148.59)$ and "Clinical Medicine in India" ( $\mathrm{AR}=146.63)$ as career aspiration featured better KAP scores compared to those students who preferred non-clinical specialties $(\mathrm{AR}=96.73)$ and or a career change $(\mathrm{AR}=76.69)(p=0.001)$.

Conclusion: The KAP questionnaire revealed inadequate readiness amongst the majority of student participants. Targeted, structured educational interventions may be recommended in order to rapidly rectify the situation and deploy medical students to supplement the frontline workers in the COVID pandemic.

Keywords: career aspirations, COVID-19, graduate medical education, India, individual attitude, survey

\section{Introduction}

Life changed for all health professionals on February 11th 2020, when the World Health Organization designated the disease COVID-19, ${ }^{1}$ when severe acute respiratory syndrome coronavirus 2 (SARS-CoV-2) rapidly spread, resulting in an epidemic throughout China, followed by a catastrophic global pandemic as designated by WHO on March 11th, 2020. As of May 2021, globally over 157 million confirmed cases of COVID-19 have been reported. ${ }^{2}$ Medical students all over the world are in a limbo; forced into digital classrooms with little clinical exposure, and with no opportunity to help frontline workers for the lack of primary qualification.
Correspondence: Manu Pradeep Department of Pharmacology, Amrita Institute of Medical Sciences, Ponekkara P.O, Kochi, 68204I, Kerala, India Tel +919947568919

Email drmanupradeep24@gmail.com 
But now, after several waves of the pandemic, their countries need them to aid their frontline workforce, but are they ready and is it fair to ask them do so?

With the impending total collapse of both the public and private health care sector during the second wave of the COVID pandemic in May 2021, the Ministry of Health and Family Welfare, Government of India has decided to conscript final year Bachelor of Medicine, Bachelor of Surgery (MBBS) medical students for supervised patient teleconsultations for asymptomatic and mildly infected patients while nursing students will be utilized for full time COVID ward duties. ${ }^{3}$ Unfortunately, to the best of our knowledge, there were no national guidelines on how to resume undergraduate medical courses, nor were there any specific mandates requiring medical students to be informed about COVID, so that they may supplement the frontline workforce when required. Medical colleges, left to their own devices, rapidly shifted to online platformbased learning which included the recently transformed "Competency based Medical education" curriculum. ${ }^{4}$ This phenomenon, replicated globally, has significantly increased the stress levels amongst all medical professionals in training - medical students and post-graduate trainees alike. ${ }^{5,6}$ There is no publicly available data that evaluated the effectiveness of these online learning modalities, in India - which has been mired by many challenges, ${ }^{4}$ and any focus on COVID-specific information is likely to vary greatly between medical schools. Other knowledge, attitude and practice (KAP) surveys done in North India revealed unsatisfactory levels of preparedness for COVID duties amongst medical students..$^{7-10}$

However, most medical students already serve the role as an important source of health information for their family and friends. The time to call upon medical students to formally educate the public on the vital messages of COVID infection preventive strategies maybe advisable, provided they are adequately informed and trained.

With added responsibility comes added stressors. Clinical medicine has always been an epitome of both physically and mentally demanding career, especially during the pandemic. It may also be perceived as a dangerous career option in the near future, evidenced by the ongoing incidences of violent assaults by bystander mobs, against health care workers in India and it may even cause medical students to abandon a career in medicine. ${ }^{11-14}$ Meanwhile, only a small fraction of students are involved in biomedical research in their undergraduate days and even less are reportedly confident in clinical research as a career option. ${ }^{15-17}$ A cross-sectional study from India reports, that those students with a higher academic acumen and those who concurrently involved in clinical research done outside the scope of their curriculum were more likely to take up research as a career option. ${ }^{18}$ However, early career researchers, with no access to a suitable patient population, have struggled immensely to conduct biomedical research as part of their clinical training, during the pandemic. $^{6}$

This cross-sectional survey was designed to gauge the KAP of medical students in South India about COVID-19. This may help in estimating the clinical readiness of medical students, who may have been limited by digital classrooms in the pandemic plagued academic year of $2020 .^{19,20}$ This is exemplified by a national survey of Indian medical students showed a prevalence of vaccine hesitancy to about $10 \%$, due to several factors. ${ }^{21}$ This study aims to discuss if their skills can be used to aid an ailing nation and also describes their career motivations, aspirations and fears at this point in time. As a novel interest, this study will examine any correlations between the cumulative KAP scores of a particular student about COVID-19, and their aspirational career choice in the pandemic and post-pandemic era.

\section{Materials and Methods Participants}

This study was conducted as a cross-sectional study via a Google Forms (Google Inc. USA) hosted questionnaire and survey, between November 1st and December 30th of 2020 amongst medical Students pursuing MBBS in South Indian Medical Colleges. Students between the age of 17 and 25 years of any gender, pursuing MBBS (medical undergraduate) courses, from any year of study (1st year to Internship) in south Indian territories/provinces (Kerala, Tamil Nadu, Karnataka, Andhra Pradesh, Telangana, Andaman \& Nicobar Islands) were included. Students of allied medical professions such Dental, Allied or Alternative Medicine streams were excluded. South Indian origin MBBS students studying in colleges not situated in South Indian territories were excluded.

The ethical approval for the study protocol, informed consent form and the survey questionnaire was obtained from the Institutional Ethics Committee of Amrita Institute of Medical Sciences-Kochi, India (IRB-AIMS-2020-318). Participants were required to read through the comprehensive informed consent form and subsequently volunteer to 
be part of this study by pressing "Yes" option on the Informed Consent section on the 1st section of the provided Google Form. Participants were assured of anonymity for their responses and encouraged to give authentic answers.

\section{Assessment}

The closed ended, multiple-choice questionnaire was created de-novo using Google Forms and was divided into three sections: 1) Demographics; 2) Knowledge (six items), Attitude (four items) and Practice (five items); and 3) Career Motivations, Pathway \& Academic aspirations. The initial draft of the questionnaire was critiqued by four academic and clinical experts from the departments of Internal Medicine and Clinical Immunology at Amrita Institute of Medical Sciences, India, who are actively involved in undergraduate medical education at the same institution. After suitable revisions were made according to the consensus of all expert opinions, the final questionnaire was validated, and underwent pilot testing in 30 medical students who were selected using simple random method to assess the reliability and to calculate the sample size of the study. Cronbach's alpha coefficient was determined to be 0.74 . The questionnaire is being attached to this manuscript as a Supplementary Material.

Medical students were purposively sampled using digital means from all over South India. Email requests to seven prominent south Indian institutional heads, and targeted promotional campaign via WhatsApp messaging and Facebook groups were launched. Invitation to participate in the study were circulated in medical student groups with a response rate of $82 \%$ (out of 415 total members). From the pilot study conducted on 30 medical students of the author's institution, the prevalence of primary outcome was detected within 25\% respondents, with 5\% margin of error and $95 \%$ confidence level. The sample size was calculated using the formula $n=z^{2} \times p(1-p) \div \epsilon^{2}$ where $\mathrm{p}$ was the prevalence $(25 \%), \in$ was the margin of error $(5 \%), \mathrm{z}$ is the $\mathrm{z}$ score and $\mathrm{n}$ is the minimum sample size which was calculated to be 289 . Of the total 340 responses received, after filtering out duplicate responses or multiple responses from a single device, applying the inclusion and exclusion criteria, 304 responses were considered for analysis.

\section{Statistical Analysis}

All responses were tabulated in MS Excel retrieved from Google Forms. This dataset was analyzed using IBM
SPSS $^{\circledR}$ Statistics version 26 (IBM Corp., Armonk, USA). Categorical data between the same groups were presented in terms of frequency count (n) and percentages (\%). Continuous variable such the KAP score of students were subdivided into 3 categories for good level (score $>$ 15), moderate level (score of 10-15) and low level (score $<10$ ) for assessing prevalence of each category. KAP variable, detected to be not normally distributed on a Shapiro-Wilk test $(\mathrm{W}=0.959$, df $=304, p<0.001)$, was preserved as continuous variable for correlation analysis and Kruskal-Wallis (ANOVA) tests was employed to detect the degree of association between career aspirations pathway and KAP score. Bonferroni correction was applied to significance values to account for the multiple simultaneous tests being done for the given alpha value. Average Rank (AR) of the various choices of students will be used to compare the direction of statistic difference between various career aspirations to KAP Scores (Higher AR indicates higher KAP score in that rank). When the data qualifies the assumptions of a Pearson's Chi square test, the association will be reported with odds ratio (OR), 95\% Confidence Interval (95\% CI) and $p$ values. $P \leq 0.05$ was set as the threshold for statistical significance for all results.

\section{Results}

Three hundred and four participants had given their informed consent of voluntary participation, completed the questionnaire and hence, were included for analysis. The demographic characteristics of the participants are detailed in Table 1.

\section{Knowledge, Attitude and Practices About COVID-19}

Question-wise results of the Knowledge section are depicted in Table 2. The mean of the cumulative scores of the Knowledge section was $7 \pm 1.48$ (Range: 1-9). $65.5 \%(n=199)$ of the participants displayed good knowledge levels. Question-wise results of the Attitudes section are depicted in Table 2. Willingness to work during the pandemic is depicted graphically in Figure 1. The mean of the cumulative scores of the Attitudes section was $4.92 \pm$ 1.15 (Range: $1-6)$. Only $51 \%(n=155)$ of the participants displayed good attitude levels. Question-wise results of the Practices section are depicted in Table 2. The mean of the cumulative scores of the Practice section was $4 \pm 0.77$ (Range: 1-5). 80.6\% $(\mathrm{n}=245)$ of the participants 
Table I Demographic Characteristics of the Study Population

\begin{tabular}{|c|c|c|}
\hline Characteristics & $\begin{array}{c}\text { Participants } \\
\quad(n=304)\end{array}$ & Percentage (\%) \\
\hline \multicolumn{3}{|l|}{ Gender } \\
\hline Male & 110 & 36.2 \\
\hline Female & 191 & 62.8 \\
\hline Prefer not to say & 3 & 1 \\
\hline Age (years) & \multicolumn{2}{|c|}{ Mean $($ Age $)=20.45 \pm 1.08$ years } \\
\hline 18 & 14 & 4.6 \\
\hline 19 & 38 & 12.5 \\
\hline 20 & 98 & 32.2 \\
\hline 21 & 115 & 37.8 \\
\hline 22 & 29 & 9.5 \\
\hline 23 & 10 & 3.3 \\
\hline \multicolumn{3}{|l|}{ Year of study } \\
\hline Ist Year & 124 & 40.8 \\
\hline 2nd Year & 146 & 48.0 \\
\hline 3rd Year & 26 & 8.6 \\
\hline 4th Year & 6 & 2.0 \\
\hline Intern & 2 & 0.7 \\
\hline \multicolumn{3}{|l|}{ State } \\
\hline Kerala & 244 & 80.3 \\
\hline Karnataka & 37 & 12.2 \\
\hline Tamil Nadu & 17 & 5.6 \\
\hline Andhra Pradesh & 5 & 1.6 \\
\hline Telangana & I & 0.3 \\
\hline \multicolumn{3}{|c|}{ Government College or Private College } \\
\hline Government College & 43 & 14.1 \\
\hline Private College & 261 & 85.9 \\
\hline
\end{tabular}

displayed good practice levels. The mean of the cumulative KAP scores of all the participant students were 14.81 $\pm 1.77 .1 .3 \%$ of the respondents had low level KAP scores, $57.2 \%$ had moderate level KAP scores and $41.4 \%$ of them had good level KAP scores.

As a result of interest, using the Mann Whitney $U$-test, the students who use medical journals to update themselves $(A R=169.24)$, independently showed statistically significant higher KAP scores compared to students who relied on other mediums to update themselves (AR =143.28, $U=12391.5, p=0.013)$. Interestingly, 129 students (42.4\%) of students reported that they had engaged in research related activities and gained some research skills during the lockdown. Ninetey-four students $(30.9 \%)$ reported that they had attended extra-curricular academic lectures and seminars conducted in online platforms by expert clinicians and epidemiologists, representing academic institutions or physician fraternities such as the Indian Medical Association. These students had higher KAP scores compared to those who did not attend such seminars but the differences were not statistically significant $(\mathrm{AR}=167.79$ vs. $146.55, U=11119, p=0.074)$.

\section{Career Aspirations}

Out of 304 students, 116 students (38.2\%) aspired to continue medical training in "Clinical medicine in India" followed by "Clinical Medicine outside India" $(\mathrm{n}=80$, $26.3 \%)$. Notably, $23.7 \%(n=72)$ of students were undecided about their future plans. Only a small fraction of students chose "Research work" ( $\mathrm{n}=15,4.9 \%)$ and "NonClinical Specialty" ( $\mathrm{n}=13,4.3 \%)$ as their aspiration currently. Eight students (2.6\%) reported that they aspired for a career change. On further examination of these eight students, $75 \%$ were from private colleges and $50 \%$ from first year of study. Furthermore, non-ideal motivations to join the program such as expectations of high pay (OR $=$ $4.38,95 \% \mathrm{CI}=0.98$ to $19.37, p=0.05$ ) and family pressure to take up the profession (OR: $14.44,95 \% \mathrm{CI}=$ 3.06 to $68.13, p=0.0007)$ appeared to be positively correlated to the choice of career change.

Students of government medical colleges (GMC) when compared to private medical colleges (PMC), preferred to pursue "Clinical Medicine in India" $(\mathrm{OR}=3.5229,95 \%$ $\mathrm{CI}=0.97$ to $12.69, p=0.054)$ whereas a significant proportion of PMC students preferred to pursue postgraduation in "Clinical Medicine outside India." "Nonclinical specialty" was preferred by those students who did not report a desire to help others, as compared to those students who chose to pursue "Clinical Medicine in India" $(\mathrm{OR}=8.62,95 \% \mathrm{CI}=2.44$ to $30.42, p=0.0008)$. Interestingly, "Clinical Medicine training in India" was preferred by those students who reported joining the UG program with a desire in the elevation of their socioeconomic class and those who did not have this motivation, were more likely to choose "Clinical Medicine training outside India" $(\mathrm{OR}=3.91,95 \% \mathrm{CI}=1.42$ to $10.75, p=$ 0.008). There seemed to be no statistical correlation between gender and current year of the study of the students, to their choice of career aspirations.

\section{KAP Scores and Career Aspirations}

Using the Kruskal-Wallis test, a strong statistical significance was detected between the KAP score and the career 
Table 2 Knowledge, Attitude, Practice (KAP) Questionnaire Results

\begin{tabular}{|c|c|c|}
\hline Questions: Knowledge $(n=304)$ & Correct Response (\%) & Incorrect Response (\%) \\
\hline QI. What is the name of the virus causing COVID-19 & 89.1 & 10.9 \\
\hline Q2. What is the mode of transmission of COVID-19? & 72.7 & 27.3 \\
\hline Q3. What is the incubation period of COVID-19? & 85.2 & 14.8 \\
\hline Q4. Is COVID-19 a zoonotic disease? & 52.3 & 47.7 \\
\hline $\begin{array}{l}\text { Q5. What distance is recommended by the government that you adhere to } \\
\text { while social distancing? }\end{array}$ & 33.6 & 66.4 \\
\hline Q6. Which are the symptoms you think are associated with COVID-19? & 95.4 & 4.6 \\
\hline Questions: Attitude $(n=304)$ & $\begin{array}{c}\text { Respondents with Good } \\
\text { Attitude (\%) }\end{array}$ & $\begin{array}{l}\text { Respondents with Poor } \\
\text { Attitude (\%) }\end{array}$ \\
\hline QI. What is your general attitude towards COVID-19? & 95.7 & 4.3 \\
\hline Q2. How do you think the pandemic can be most effectively contained? & 92.7 & 7.3 \\
\hline Q3. What would you do in your power as a medical student? & 100 & - \\
\hline $\begin{array}{l}\text { Q4. If you had been working during this pandemic, what would your possible } \\
\text { course of action have been? }\end{array}$ & 55.1 & 44.9 \\
\hline Questions: Practice $(n=304)$ & $\begin{array}{l}\text { Respondents with Good } \\
\text { Practice (\%) }\end{array}$ & $\begin{array}{l}\text { Respondents with Poor } \\
\text { Practice (\%) }\end{array}$ \\
\hline QI. Do you follow the social distancing guidelines issued by your government? & 96.7 & 3.3 \\
\hline Q2. How often do you wear a mask when going out? & 92.4 & 7.6 \\
\hline Q3. If you were quarantined, what would you do? & 89.8 & 10.2 \\
\hline Q4. For what reasons do you go outside? & 86.1 & 13.9 \\
\hline Q5. How do you keep yourself updated? & 35.6 & 64.4 \\
\hline
\end{tabular}

choices of medical students $(\mathrm{n}=304, H=20.075$, $\mathrm{df}=5$, $P=0.001)$ with "Research Work" and "Clinical Medicine outside India" featuring the best AR of KAP scores with 192.70 and 173.64 respectively. "Undecided" and "Clinical Medicine in India" scored an AR of 148.59 and 146.63 respectively. "Non-Clinical Specialty" and "Career
Changes" scored poorly with AR scores of 96.73 and 76.69 respectively. This is depicted graphically in a boxplot (Figure 2).

Upon further inspecting the associations between the student choices, students who had chosen "Research Work" $(\mathrm{H}=-116.012, \mathrm{AR}=192.70, p=0.034)$ and
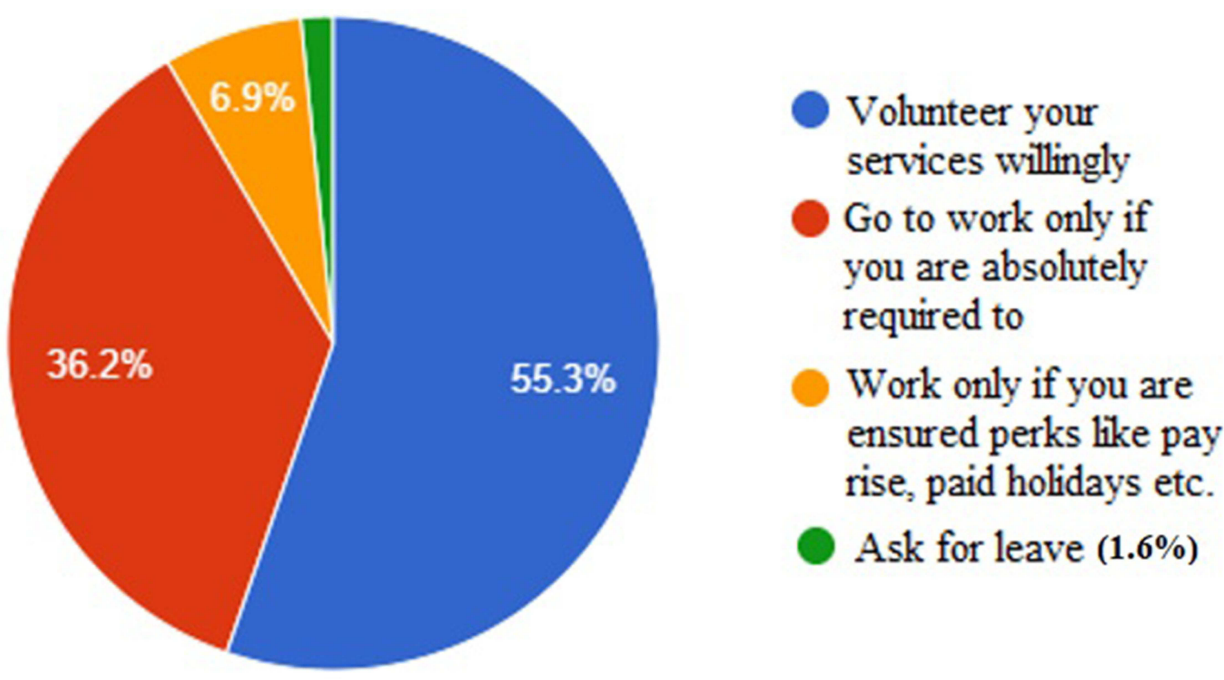

Figure I Response to Section $2 \mathrm{~b}$ Q4: If you had been working during this pandemic, what would your possible course of action have been? 


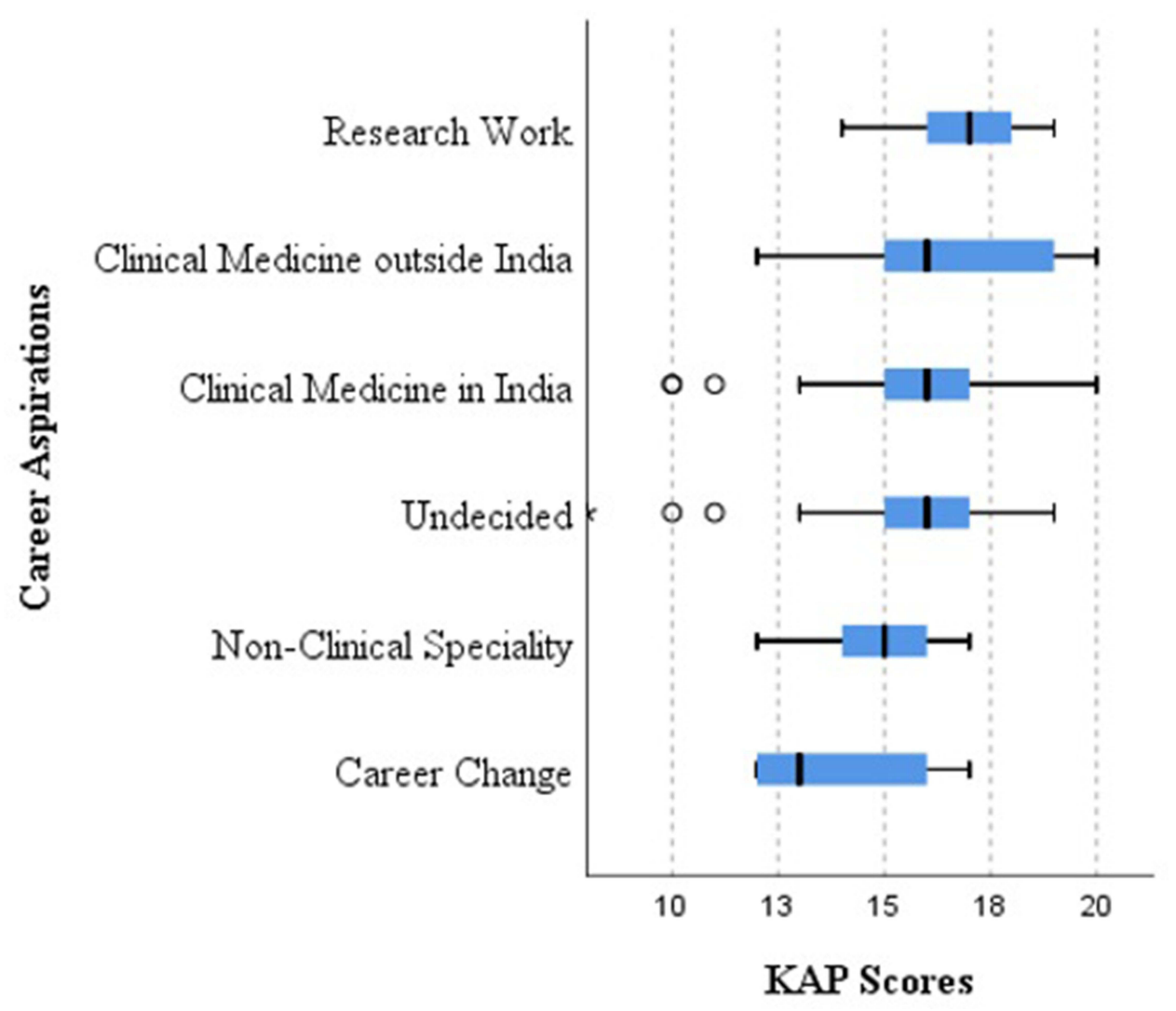

Figure 2 KAP scores (Maximum - 20 points) vs. Career aspirations using the Kruskal Wallis test. ( $N=304)$. "Clinical medicine in India" $(n=116)$, "Clinical Medicine outside India" $(n=80)$, Undecided $(n=72)$, "Research work" $(n=15)$, "Non-Clinical Specialty" $(n=13)$, "Career Change" $(n=8)$.

"Clinical Medicine outside India" as a career aspiration $(\mathrm{H}$ $=-96.956, \mathrm{AR}=173.64, p=0.039)$, displayed statistically significant positive association and higher KAP scores, when compared independently to those students who opted for "Career Change" (AR = 76.69). Students who had chosen "Clinical Medicine outside India" also displayed statistically significant positive association and higher KAP values, when compared to students who chose "Non-Clinical Specialty" $(\mathrm{H}=-76.913$, AR $=$ 173.64 vs. $\mathrm{AR}=96.73, p=0.046$ ). A particular pairing of interest, which has been narrowly deemed statistically insignificant $(P=0.053)$, "Non-Clinical Specialty" $(\mathrm{AR}=$ 96.73) when compared with "Research Work" (AR = 192.70) should be considered a significant output nonetheless considering the large difference in AR between them. Detailed pairwise associations between career choices have been depicted (Figure 3).

A Kruskal-Wallis $H$-test showed that there was a statistically significant difference in KAP score between the different reported genders, $\mathrm{H}=16.33, p \leq 0.001$, with an AR (KAP score) of 167.98 for Female, 126.18 for Male and 132 for "Prefer not to say."
Analysis done using the Mann Whitney $U$-Test revealed no statistically significant association found between KAP scores amongst private or government managed medical colleges in South India $(U=4645.5, p=$ 0.366). Furthermore, Kruskal Wallis test depicted that there was no statistically significant association of KAP score with either the year of study of medical students $(\mathrm{H}$ $=1.912, \mathrm{df}=4, p=0.752)$ or the State which hosts their medical college $(\mathrm{H}=3.628, \mathrm{df}=4, p=0.459)$.

\section{Discussion}

This cross-sectional survey was conducted on 304 medical students in South India and $65.5 \%$ of participants had good knowledge (K) levels, 51\% had good attitude (A) scores and $80.6 \%$ had good practice $(\mathrm{P})$ scores. This is roughly comparable to other studies done in other parts of India and in Bangladesh; such as in Gohel et al 2021 ( $\mathrm{K}=$ $60.47 \%$ and Perception $=40.9 \%$ ), Modi et al 2020 (Total K.A.P of Medical undergraduates $=74.2 \%$ ) and Wadood et al $(\mathrm{K}=70.7 \%, \mathrm{~A}=68.9 \%, \mathrm{P}=54.8 \%)^{8,10,22}$ In contrast, similar studies conducted by Peng et al 2020 in China $(\mathrm{K}=82.34 \%, \mathrm{~A}=73.81 \%, \mathrm{P}=87.9 \%)$ and Olum 


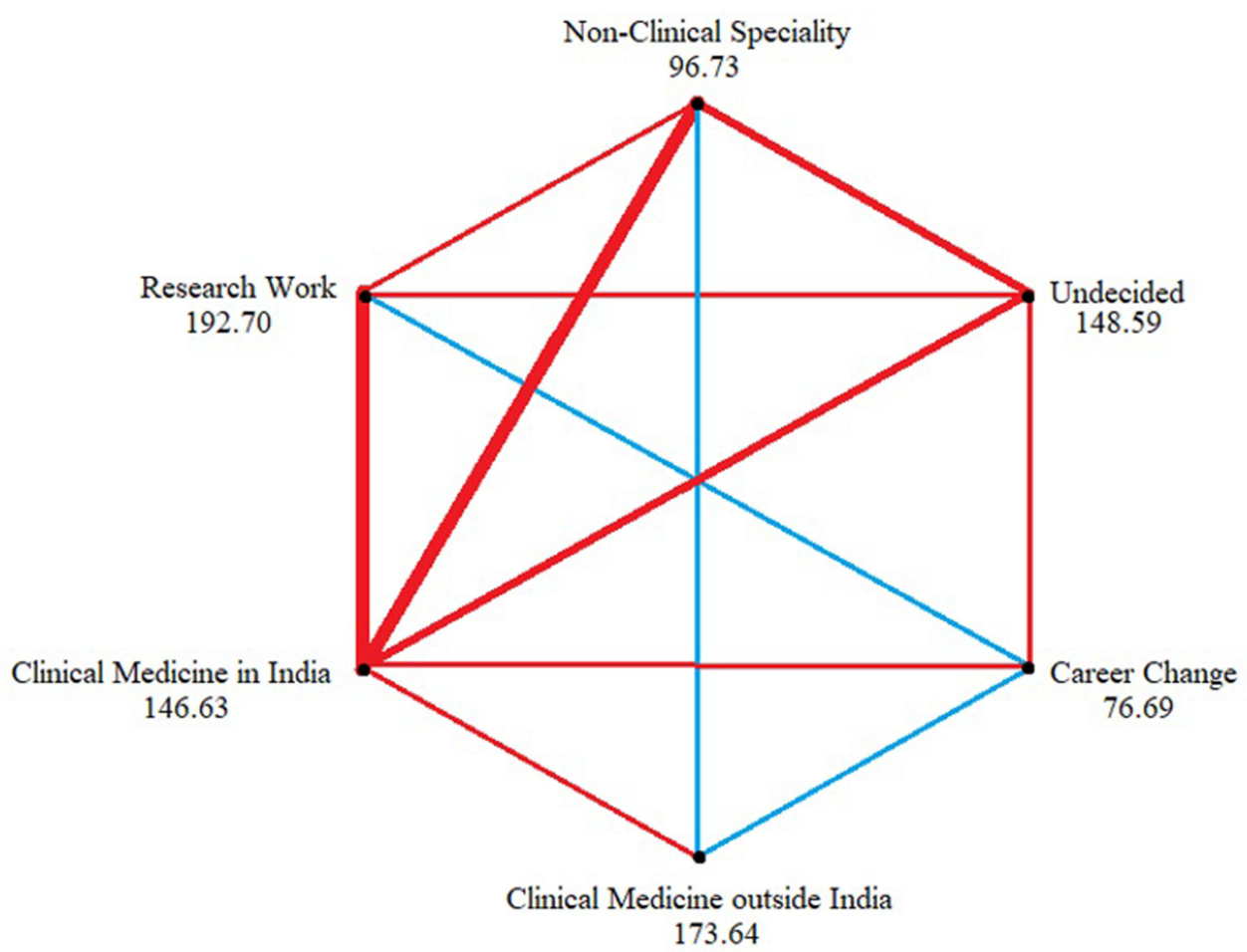

Figure 3 Pairwise comparison of career aspirations vs. KAP scores. Each node shows the sample AR of career pathway choices. Blue lines depict statistically significant correlations. Red lines depict statistically non-significant correlations (with thicker lines showing relatively stronger correlations) $(\mathrm{N}=304)$. "Clinical medicine in India" ( $\mathrm{n}=$ I16), "Clinical Medicine outside India" $(n=80)$, Undecided $(n=72)$, “Research work" $(n=15)$, “Non-Clinical Specialty" $(n=13)$, “Career Change" $(n=8)$.

et al 2020 in Uganda $(\mathrm{K}=91 \%, \mathrm{~A}=74 \%, \mathrm{P}=57 \%)$ showed much higher knowledge scores. ${ }^{23,24}$ Whereas similar studies conducted by Salman et al $(\mathrm{K}=50.2 \%$, $\mathrm{A}=65.4 \%, \mathrm{P}=36.5 \%)$ in Pakistan, and by Alnohair et al $2020(\mathrm{~K}=38 \%, \mathrm{~A}=55 \% .2, \mathrm{P}=24 \%)$ in Medical Interns of Saudi Arabia, show lower KAP scores. ${ }^{25,26}$ These gross differences may be partly attributable to the significant difference in study populations, cultural differences in questionnaire administered, scoring and threshold used for good KAP selected by the authors. Thus, conclusive differences or inferences may not be reliably elicited between the study populations with these results alone. This highlights a need for a region/province-wise, culture specific, standardized, validated KAP questionnaire that maybe utilized by state governments to screen for COVID duty ready medical students. This study estimates that only $41.4 \%$ of the study population to possess a good KAP score and may serve as a valuable supplemental workforce to the frontline. Further educational interventions, such as a "Fundamentals on COVID" series with a special emphasis on critical appraisal of the latest published scientific literature by experts maybe ideal for this urgent scenario.
As with any educational intervention, post-session assessment scores of all participating students must be captured and those who qualify may be used to rapidly build up of a volunteer "student workforce" for their short-term deployment. Their participation efforts can be motivated by providing accredited certification for completing relevant training. National recognition for their volunteer work, similar to how medical professionals are now offered the Prime Minister's "Distinguished Covid National Service Samman", after completing 100 days of COVID clinical duty, may result in increased interest from the medical student fraternity. ${ }^{27}$

As expected in the current research hypothesis of this study, use of Journals and other verified sources results in a statistically significant higher KAP scores in medical students. Only $35.9 \%$ of our respondents said that they got information about COVID from journals and other formal sources, whereas $78.6 \%$ used social media for the same. In contrast, Saudi Arabian study (Alnohair et al), $76 \%$ of the respondents got their information from formal sources like official websites of national and international bodies. In a Sudanese study (Olum et al), the respondents reported their information sources about COVID as television and social media ( $79 \%$ and $76 \%$ ) respectively. In 
similar studies from North India, Gohel et al reported that $65.17 \%$ of the participants said their source of information was social media while another study, Singh et al reported that $82.1 \%$ of the participants reported that they heard about COVID-19 from popular media. ${ }^{9,10}$ This is a worrying global trend, due to the popularity and ease of use of several social media platforms, young undergraduates are not immune to its appeal.

In this study, students who demonstrated a sub-optimal knowledge of COVID-19 in a certain aspect (e.g., 66.4\% incorrectly replied to the distancing rules as dictated by the government), also reported that they practice governmental guidelines (96.4\%). This dissonance between the knowledge and practice maybe suggest that some medical students may consider certain unverified sources to be legitimate. Supposed "scientific" information is being disseminated to young and receptive professionals in training, from unverified and potentially malicious sources. But the solution will not be restricting social media usage in medical students. Social media can serve as positive impact too, such as to meet likeminded budding academics and research partners. Educators must guide their students to compartmentalize their academic and social life; provide tips to use social media to discover, discuss and debate emerging ideas. Biomedical research must be introduced and encouraged in all freshers, including an ability to critically appraise information will prove vital in limiting the spread of misinformation and disinformation about COVID, and perhaps turn the tide against it by these future professionals.

Indian medical education was undergoing a metamorphosis by adapting a "Competency Based Medical education" model in 2019, but the pandemic threw this process into disarray. The hastily rolled out online platforms compounded the pressures on a new system, with: 1) no scope for students to develop real clinical skills; 2) poor time management - causing burnout amongst teachers; 3) lack of infrastructure- especially in government run medical colleges; 4) Poor communication - teachers were left to conduct classes on their own, with little support or coordination from the administration; 5) Negative attitude - both teachers and students faced technical issues often; and 6) Poor student engagement when learning was not followed up with clinical practice. ${ }^{4}$ All these challenges, may have fatigued the medical students and left them uninformed about COVID-19. Any information gained, may have been through passive routes, such as government led social media awareness campaigns, often featured right alongside other questionable sources.

As demonstrated in Modi et al 2020, Peng et al 2020, Wadood et al 2020, Olum et al 2020 and Alnohair et al 2020, this study also shows a significant association of female gender to higher KAP scores. This is concordance with the results from similar studies conducted during H1N1, SARS, and MERS outbreaks. ${ }^{23}$ Notably, there was no statistically significant differences in KAP scores between government vs. privately managed medical colleges, across different academic year of study or states hosting medical colleges. This may again suggest that students may be relying on extracurricular sources for their COVID information, such as social media and the general public news With no national guidelines for medical education during the pandemic, the absence of the expected inter-year and inter-college differences in KAP scores suggest that students are indeed more reliant on non-academic sources. In general, a significant difference is expected in academic support, that a student receives in a government medical college when compared to a private medical college, in India.

When asked about rendering their services in the frontline, only $55.1 \%$ of our participants were willing to work in the frontline, which was similar to a US-based study. ${ }^{28} \mathrm{In}$ contrast to this finding, a large proportion of Chinese medical students $(93.1 \%)$ and Ugandan students $(80 \%)$ were willing to participate in the frontline care if need be..$^{23,24}$ This stark difference maybe be directly linked to the lack luster KAP scores of this student population compared to the others. Understandably, many of them are hesitant, as most of them acquired their knowledge from informal sources and this may limit their confidence to reliably supplement the frontline workforce in a real-life scenario.

As reported in pre-pandemic studies, the students of this study also overwhelmingly preferred a clinical medicine training pathway (either in India or abroad) over nonclinical specialty. Alarmingly, $26.3 \%$ of students in the current study reported that they plan to continue their postgraduate training outside India as compared to $7 \%$ in an Indian study conducted in $2010 .{ }^{29}$ This could signify a massive, ongoing loss of highly trained professionals to other countries - A so-called "brain drain" from India. A large, young medical workforce is sorely needed for the battered health care sector now, more than ever. Of 304 students, eight reported that they were contemplating a career change, mostly freshers from private colleges. They had poor primary motivations for joining the undergraduate program like 
expectations of high pay later in their career and more, significantly, family pressure to take up the career.

As hypothesized, students aspiring to be Clinical Researchers and pursuing Clinical Medicine scores significantly higher KAP scores about COVID than those students who preferred non-Clinical specialties and those who wanted a career change. This is illustrative of the fact that students who are inclined to clinical subjects, are more likely to be equipped for supplementing the frontline workers. Innovative teaching methods need to be devised in order to reach through to students primarily interested in non-clinical specialties, as COVID remains a very much a clinical problem in India for now. Further studies are needed to evaluate the needs of these low scoring sub-population of students, especially those students who are planning a career change, so as to not lose valuable human resources in this pandemic.

The factors limiting the internal validity of this study is the online, cross- sectional study design. External validity is restricted, as students who responded were unevenly distributed amongst different medical colleges, however analysis did not reveal a statistical difference in KAP, between them. A medical student's grade in clinical subjects may be an important confounder for their KAP score and their career selection, thus future researchers may include a baseline grade for these subjects as a covariate.

Due to the currently ongoing second wave of the COVID19 pandemic in India, telephonic follow-up of suspected or confirmed patients with mild COVID disease being monitored at home, are being assigned to senior medical students. Unfortunately, in this study, the results illustrate that medical students in general, are lacking in basics of COVID-19 and need much more training, orientation and motivation if they are to be effectively used to supplement any frontline efforts in the pandemic. In the short term, premature deployment of these students to any pandemic related task is speculated to lead to poorer outcomes for public health as well as to the students, who are already facing a declining mental health and risk of burnout. However, as a first step, all medical students must be trained and encouraged to critically appraise biomedical research so that they may confidently inform the general public about all matters regarding the pandemic (including recent advances), preferably combating misinformation in the social media. As educators and students continue to struggle and adapt to e-learning modalities, a comprehensive module on COVID-19 is urgently warranted. It may then be advisable to devise a region/province-wise, cultureappropriate, validated, questionnaire by medical educators around India, to assess the "COVID Duty" readiness of medical students. Only such medical students who are properly informed, maybe further trained and allowed to volunteer for any specific frontline duties. In the medium-term, as a safety net, students assigned to such tasks should be monitored for signs of distress and offered relevant, regular training sessions. In the long term, a potentially devastating loss of highly trained medical workforce may be imminent in the future of Indian health sector, as medical students are increasingly looking to emigrate out to western countries for postgraduate training and better career prospects.

\section{Acknowledgments}

The authors are grateful to the Dr. Col. Vishal Marwah, Principal, Amrita School of Medicine, AIMS Kochi, for his mentorship, and providing academic as well as statistical support of his team. The team also wishes to mark our gratitude for Dr. Bindu M.R, Associate Professor, Department of Pathology, AIMS Kochi for her valuable proofreading and comments. The authors are also indebted to the medical student participants for sparing their time, to be part of the study.

\section{Disclosure}

The authors report no conflicts of interest in this work.

\section{References}

1. Ghebreyesus TA. WHO Director-General's remarks at the media briefing on 2019-nCoV on 11 February 2020. WHO Director General's Office; 2020. Available from: https://www.who.int/director-general/speeches/ detail/who-director-general-s-remarks-at-the-media-briefing-on-2019ncov-on-11-february-2020. Accessed May 08, 2021.

2. Johns Hopkins University. COVID-19 map. Coronavirus Resource Center; 2021. Available from: https://coronavirus.jhu.edu/map.html. Accessed May 08, 2021.

3. Amit Biswas and U. S. to the G. of India. Augmenting human resources for COVID - 19. Ministry of Health and Family Welfare, Govt. of India. Available from: https://www.mohfw.gov.in/pdf/ LettertoStatesUTsonHealthWorkForce.pdf. Accessed May 09, 2021.

4. Nimavat N, Singh S, Fichadiya N, et al. Online medical education in India - different challenges and probable solutions in the age of COVID19. Adv Med Educ Pract. 2021;12:237. doi:10.2147/AMEP.S295728

5. Puranachaikere T, Hataiyusuk S, Anupansupsai R. Stress and associated factors with received and needed support in medical students during COVID-19 pandemic: a multicenter study. Korean J Med Educ. 2021;33(3):203-213. doi:10.3946/KJME.2021.200

6. Nagendrappa S, de Filippis R, Ramalho R, et al. Challenges and opportunities of psychiatric training during COVID-19: early career psychiatrists' perspective across the world. Acad Psychiatr. 2021;2021:1-2. doi:10.1007/S40596-021-01482-3

7. Maheshwari PK, Gupta RS, Rawat P, Rawat P. Knowledge, attitude, and practice towards coronavirus disease 2019 (COVID-19) among medical students: a cross-sectional study. J Acute Dis. 2020;9(3):100. doi:10.4103/2221-6189.283886

8. Modi PD, Nair G, Uppe A, et al. COVID-19 awareness among healthcare students and professionals in mumbai metropolitan region: a questionnaire-based survey. Cureus. 2020;12(4). doi:10.7759/ cureus. 7514 
9. Singh A, Panika R, Surana A, Gupta V, Goyal P, Singh M. Evaluation of knowledge and perceptions among medical undergraduate students toward novel coronavirus (COVID-19) in Southern Haryana, India: a cross-sectional study. Indian J Health Sci Biomed Res. 2020;13 (2):91. doi:10.4103/kleuhsj.kleuhsj_120_20

10. Gohel KH, Patel PB, Shah PM, Patel JR, Pandit N, Raut A. Knowledge and perceptions about COVID-19 among the medical and allied health science students in India: an online cross-sectional survey. Clin Epidemiol Glob Health. 2021;9:104-109. doi:10.1016/j. cegh.2020.07.008

11. Iyengar KP, Jain VK, Vaishya R. Current situation with doctors and healthcare workers during COVID-19 pandemic in India. Postgrad Med J. 2020. doi:10.1136/postgradmedj-2020-138496

12. Gupta S, Sahoo S. Pandemic and mental health of the front-line healthcare workers: a review and implications in the Indian context amidst COVID-19. Gen Psychiatr. 2020;33(5):e100284. doi:10.1136/ gpsych-2020-100284

13. Sood R, Singh G, Arora PK. To study medical students' perspective on rising violence against doctors. Do they consider obstetrics and gynecology a risky branch? Int J Reprod Contracept Obstetr Gynecol. 2017;6(8):3314. doi:10.18203/2320-1770.ijrcog20173193

14. J B, M P, S S, V T. Study on violence against doctors and its impact on career selection. Int J Adv Commun Med. 2020;3(3):14-17. doi:10.33545/comed.2020.v3.i3a.153

15. Deo M. Undergraduate medical students' research in India. J Postgrad Med. 2008;54(3):176-179. doi:10.4103/0022-3859.41796

16. Zodpey SP, Negandhi HN. Training in clinical research in India: potential and challenges. Indian $J$ Commun Med. 2009;34 (3):173-174. doi:10.4103/0970-0218.55267

17. Sharma K, Jindal A. Low awareness of clinical research in India amongst final year medical students and physicians: need for increased emphasis on clinical research in medical curriculum. Archiv Med Health Sci. 2014;2(2):234. doi:10.4103/23214848.144359

18. Harsha Kumar H, Jayaram S, Kumar G, et al. Perception, practices towards research and predictors of research career among UG medical students from coastal South India: a cross-sectional study. Indian J Commun Med. 2009;34(4):306. doi:10.4103/0970-0218.58388

19. Bala R, Gupta N, Sharma R, Narang U, Joshi S, Navid CN. Medical student's perception and feed-back on virtual classes during COVID19 pandemic: a multi-centric questionnaire based study Introduction. Int J Health Clin Res. 2020;3(4):93-96.
20. Raj U, Fatima A. Stress in students after lockdown due to COVID-19 threat and the effects of attending online classes. SSRN Electron J. 2020. doi: $10.2139 / \mathrm{ssrn} .3584220$

21. Jain J, Saurabh S, Goel AD, Gupta K, Bhardwaj P, Raghav PR. COVID-19 vaccine hesitancy among undergraduate medical students: results 2 from a nationwide survey in India. medRxiv. 2021. doi:10.1101/2021.03.12.21253444

22. Wadood MA, Mamun AS, Rafi MA, et al. Knowledge, attitude, practice and perception regarding COVID-19 among students in Bangladesh: survey in Rajshahi University. medRxiv. 2020. doi:10.1101/2020.04.21.20074757

23. Peng Y, Pei C, Zheng Y, et al. A cross-sectional survey of knowledge, attitude and practice associated with COVID-19 among undergraduate students in China. BMC Public Health. 2020;20(1). doi:10.1186/ s12889-020-09392-Z

24. Olum R, Kajjimu J, Kanyike AM, et al. Perspective of medical students on the COVID-19 pandemic: survey of nine medical schools in Uganda. JMIR Public Health Surveill. 2020;6(2):1-12. doi:10.2196/19847

25. Salman M, Mustafa ZU, Asif N, et al. Knowledge, attitude and preventive practices related to COVID-19: a cross-sectional study in two Pakistani university populations. Drugs Ther Perspect. 2020;36(7):319-325. doi:10.1007/s40267-020-00737-7

26. Alnohair F, Alshehri F, Alshuqayran R, Albatanouni M. Knowledge, attitudes, and practices of medical interns toward COVID-19 in Saudi Arabia: a cross-sectional survey, April-May 2020. BMC Public Health. 2020. doi:10.21203/rs.3.rs-48682/v1

27. G. of India. Prime Minister's Office, PM authorises keys decisions to boost availability of medical personnel to fight COVID-19. Press Information Bureau; 2021. Available from: https://pib.gov.in/ PressReleseDetail.aspx?PMO $=3 \& \mathrm{PRID}=1715667$. Accessed May 30, 2021.

28. Appelbaum NP, Misra SM, Welch J, Humphries MH, Sivam S, Ismail N. Variations in medical students' educational preferences, attitudes and volunteerism during the COVID-19 global pandemic. $J$ Community Health. 2021;2021:1-9. doi:10.1007/S10900-02101009-9

29. Diwan V, Minj C, Chhari N, de Costa A. Indian medical students in public and private sector medical schools: are motivations and career aspirations different? - Studies from Madhya Pradesh, India. BMC Med Educ. 2013;13(1):1-6. doi:10.1186/1472-6920-13-127
Advances in Medical Education and Practice

\section{Publish your work in this journal}

Advances in Medical Education and Practice is an international, peerreviewed, open access journal that aims to present and publish research on Medical Education covering medical, dental, nursing and allied health care professional education. The journal covers undergraduate education, postgraduate training and continuing medical education including emerging trends and innovative models linking education, research, and health care services. The manuscript management system is completely online and includes a very quick and fair peer-review system. Visit http://www.dovepress.com/testimonials.php to read real quotes from published authors. 